Check for updates

Cite this: Nanoscale Adv., 2019, 1, 2546

\title{
Extracting structural information of Au colloids at ultra-dilute concentrations: identification of growth during nanoparticle immobilization $\uparrow$
}

\author{
George F. Tierney, (D) ab Donato Decarolis, ${ }^{\text {ab }}$ Norli Abdullah, (D) bcd \\ Scott M. Rogers, (D) bd Shusaku Hayama, ${ }^{\text {e }}$ Martha Briceno de Gutierrez, ${ }^{f}$ \\ Alberto Villa, (D) ${ }^{9}$ C. Richard A. Catlow, ${ }^{\text {bdh }}$ Paul Collier, ${ }^{f}$ Nikolaos Dimitratos (DD ${ }^{* i}$ \\ and Peter P. Wells (D) *abe
}

\begin{abstract}
Sol-immobilization is increasingly used to achieve supported metal nanoparticles (NPs) with controllable size and shape; it affords a high degree of control of the metal particle size and yields a narrow particle size distribution. Using state-of-the-art beamlines, we demonstrate how $X$-ray absorption fine structure (XAFS) techniques are now able to provide accurate structural information on nano-sized colloidal $\mathrm{Au}$ solutions at $\mu \mathrm{M}$ concentrations. This study demonstrates: (i) the size of Au colloids can be accurately tuned by adjusting the temperature of reduction, (ii) Au concentration, from $50 \mu \mathrm{M}$ to $1000 \mu \mathrm{M}$, has little influence on the average size of colloidal Au NPs in solution and (iii) the immobilization step is responsible for significant growth in Au particle size, which is further exacerbated at increased $\mathrm{Au}$ concentrations. The work presented demonstrates that an increased understanding of the primary steps in sol-immobilization allows improved optimization of materials for catalytic applications.
\end{abstract}

Received 14th March 2019

Accepted 11th May 2019

DOI: 10.1039/c9na00159j

rsc.li/nanoscale-advances

\section{Introduction}

The study of supported metal nanoparticles (NPs) is a cornerstone of heterogeneous catalysis; their reduced size, distribution of surface sites, and interaction with metal oxide supports afford enhanced catalytic properties as well as providing effective use of noble metals. ${ }^{1-5}$ Within the various routes typically used to produce supported metal NPs, the application of solimmobilization is becoming increasingly popular; it offers

${ }^{a}$ School of Chemistry, University of Southampton, Highfield, Southampton, SO17 1BJ, UK. E-mail:P.P.Wells@soton.ac.uk

${ }^{b} U K$ Catalysis Hub, Research Complex at Harwell, Rutherford Appleton Laboratory, Harwell, Didcot, OX11 OFA, UK

'Department of Chemistry, Center for Foundation Science, National Defense University of Malaysia, Sungai Besi Camp, 57000 Kuala Lumpur, Malaysia

${ }^{d}$ Department of Chemistry, University College London, 20 Gordon Street, London, WC1H OAJ, UK

${ }^{e}$ Diamond Light Source, Harwell Science and Innovation Campus, Chilton, Didcot, OX11 ODE, UK

fJohnson Matthey Technology Centre, Sonning Common, Reading, RG4 9NH, UK

${ }^{8}$ Dipartimento di Chimica, Universitá degli Studi di Milano, via Golgi 19, 20133 Milano, Italy

${ }^{n}$ Cardiff Catalysis Institute, School of Chemistry, Cardiff University, Cardiff, CF10 3AT, UK

'Dipartimento di Chimica Industriale "Toso Montanari”, Alma Mater Studiorum Università di Bologna, Viale Risorgimento 4, 40136 Bologna, Italy. E-mail: nikolaos. dimitratos@unibo.it

$\dagger$ Electronic supplementary information (ESI) available. See DOI: $10.1039 / \mathrm{c} 9 \mathrm{na} 00159 \mathrm{j}$ a high degree of tunability through the nature of stabilising or reducing agents, ${ }^{6-11}$ temperature of synthesis, ${ }^{5,12-16}$ solvent system, ${ }^{5,16,17}$ or concentration of the metal precursor salt. ${ }^{18}$

There have been many elegant studies that have assessed the influence of these parameters, primarily relying upon advanced electron microscopy to provide structural information on the final supported catalyst. ${ }^{3,19,20}$ However, to understand better the preparation of supported NPs through sol-immobilization, further insights into all steps in the process are needed. $\mathrm{Au}$ NPs are one of the most intensely studied nano-particulate systems due to the wide range of potential applications, from medicine to catalysis. ${ }^{21}$ Recent approaches to study the structural properties of colloidal solutions of Au NPs, have utilised high brilliance X-rays, produced by synchrotron radiation, for small angle X-ray scattering (SAXS) and X-ray absorption fine structure (XAFS) investigations. Much work in this area has followed the formation of Au NPs using time-resolved studies; ${ }^{21-26}$ the intention is to understand the principal steps in the evolution from defined precursors to NP entities. Using XAFS, these studies have assessed the formation of Au NPs from precursor Au solutions with concentrations ranging between 7 and $100 \mathrm{mM},{ }^{21,25-31}$ with data acquisition times ranging between minutes and hundreds of ms. They have continually increased their sophistication, moving from simple sample environments, such as a large volume cells, towards precision engineered microfluidic reactors ${ }^{28,29}$ or acoustic levitation systems. ${ }^{21}$

Other than XAFS, SAXS has proved successful in studying colloidal Au NP systems. $^{21,24}$ It allows for very fast 
measurements, in the order of milliseconds, and is able to provide information regarding the particle size and shape during the reaction procedure. ${ }^{24,32}$ However, the resolution for SAXS is limited to sizes $\geq 1 \mathrm{~nm},{ }^{33}$ below which meaningful data cannot be extracted. Moreover, a sufficient concentration, $\geq 200$ $\mu \mathrm{M},{ }^{23}$ is needed to achieve the required electronic contrast. As a consequence, the concentrations of $\mathrm{Au}$ precursors employed in these XAFS and SAXS studies do not always reflect the typical conditions found in the recent literature for the preparation of $\mathrm{Au}$ NPs, e.g. 5-100 $\mu \mathrm{M} .^{16,34-41}$ At such low concentrations, the application of these forms of characterization becomes challenging.

Furthermore, these studies do not explore the changes to the properties of the NPs once they have been supported. It is well known that there is a special interplay between metal NPs and their supports; the strong metal-support interaction, ${ }^{\mathbf{4 2}}$ and wettability ${ }^{43}$ influence the properties of the NPs once immobilised. ${ }^{43-46}$ To understand how best to optimise the catalytic performance of supported NPs it is important to separate the contributions of synthesis conditions during the colloidal step and immobilization on the resultant colloidal NP structures.

In this work, XAFS studies (Fig. 1) of colloidal Au solutions prepared at different temperatures $\left(1{ }^{\circ} \mathrm{C}, 25{ }^{\circ} \mathrm{C}, 50{ }^{\circ} \mathrm{C}, 75^{\circ} \mathrm{C}\right)$ and concentrations $(50 \mu \mathrm{M}, 100 \mu \mathrm{M}, 1000 \mu \mathrm{M})$ have been performed. This study assesses the structural properties of colloidal $\mathrm{Au}$ solutions at more relevant concentrations than previously reported and allows for the unique contributions of colloidal $\mathrm{Au}$ generation and the subsequent immobilization step to be disentangled.

\section{Experimental section}

\section{Materials and methods}

Catalyst preparation. Preparation of colloidal and supported Au NPs was performed using a conventional sol-immobilization method; concentration of the Au metal salt precursor and the temperature during the reduction processes were altered. $\mathrm{HAuCl}_{4}$ was used in preparation of the colloidal solutions at specific concentrations using deionised water $(18.2 \mathrm{M} \Omega \mathrm{cm})(50$ $\mu \mathrm{M}, 100 \mu \mathrm{M}$ and $1000 \mu \mathrm{M}$ ); PVA was added as the stabilising agent (1 wt\% solution, Aldrich, MW = 9000-10 $000 \mathrm{~g} \mathrm{~mol}^{-1}$, $80 \%$ hydrolysed, PVA/Au (wt. ratio $=0.65)$ ). Solutions of $\mathrm{NaBH}_{4}$ (0.1 M) $>96 \%$, Aldrich, $\mathrm{NaBH}_{4} / \mathrm{Au}$ (molar ratio = 5) were subsequently added drop-wise over the course of a minute, under continuous stirring evolution of dark red sols was observed. Formation of colloidal Au NPs occurred after a 30 minute time period and studied by UV-vis spectroscopy and XAFS. $\mathrm{TiO}_{2}$ stabilised colloids (0.99 g P25, Degussa), were prepared, with a calculated amount of $\mathrm{TiO}_{2}$ added to give a final metal loading of $1 \mathrm{wt} \%$. The supported $\mathrm{Au} / \mathrm{TiO}_{2}$ mixture was acidified to $\mathrm{pH}$ 1-2 using $\mathrm{H}_{2} \mathrm{SO}_{4}$ before a 60 minute period under vigorous stirring, ensuring full immobilization of the $\mathrm{Au}$ NPs on $\mathrm{TiO}_{2}$; the mixture was filtered, washed with distilled water and dried overnight at room temperature. The different temperature and concentrations used in synthesis of the catalysts in this paper are listed in Table 1.

UV-visible spectroscopy. Evolution of the colloidal hydrosols were analysed by UV-vis spectroscopy to determine the position of the gold surface plasmon resonance (SPR) band. Generation of the Au colloid SPR bands were recorded using a Shimadzu UV-1800 spectrometer in a quartz cuvette after $30 \mathrm{~min}$ of colloid formation.

X-ray absorption fine structure (XAFS). XAFS measurements of both colloidal and $\mathrm{TiO}_{2}$ supported Au NPs at the Au $\mathrm{L}_{3}$-edge were performed on the scanning branch of the I20 beamline at the Diamond Light Source, Didcot, U.K. Colloidal Au NPs were studied in a continuous flow using an adapted stainless steel cell (Fig. 1); $1 / 16^{\text {th }}$ outer diameter PTFE tubing and peristaltic pump were used to continuously move the solution through the cell, with Kapton window in place as X-ray transparent a)

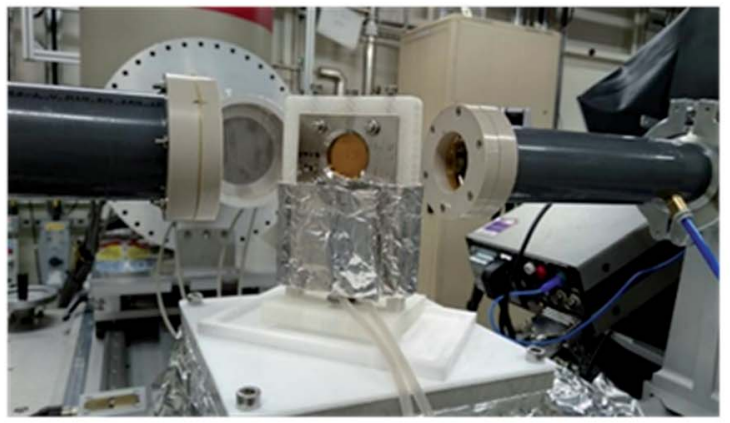

b)

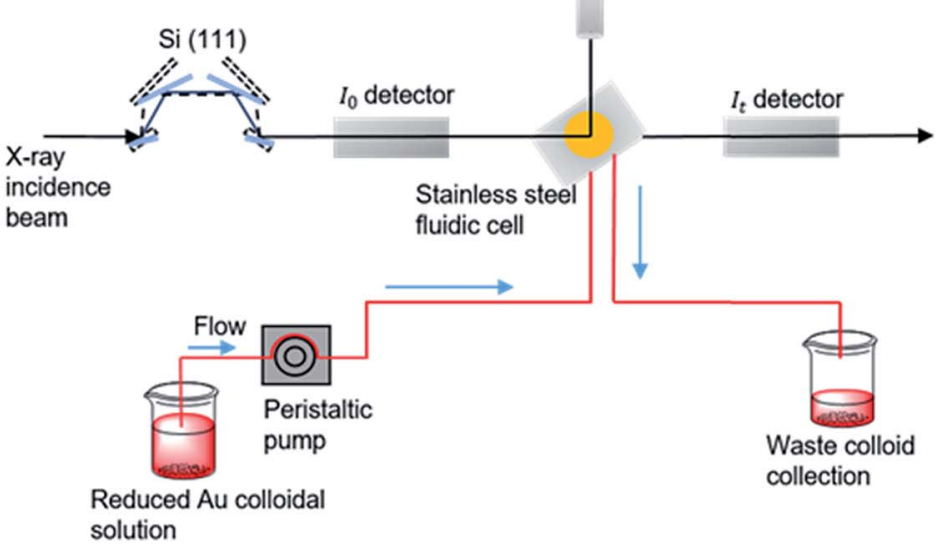

Fig. 1 (a) Photograph of the in situ cell on the 120 beamline. (b) Experimental schematic for data acquisition of colloidal Au XAFS at the I20 beamline at the Diamond Light Source, Didcot, UK. A continuous flow of preformed colloid was pumped through PTFE tubing and XAFS data was acquired in fluorescence mode by a solid state Ge detector. ${ }^{48,66}$ 
Table 1 Au SPR band maximum and average NP diameters calculated through TEM and EXAFS analysis

\begin{tabular}{|c|c|c|c|c|c|c|c|c|c|}
\hline \multirow[b]{2}{*}{$\begin{array}{l}\text { Sample } \\
\text { name }\end{array}$} & \multirow{2}{*}{$\begin{array}{l}\text { Temperature } \\
\text { of } \\
\text { preparation } \\
\left({ }^{\circ} \mathrm{C}\right)\end{array}$} & \multirow[b]{2}{*}[\mathrm{Au}]{$(\mu \mathrm{M})$} & \multirow[b]{2}{*}{$\begin{array}{l}\text { UV-vis max } \\
(\mathrm{nm})\end{array}$} & \multicolumn{3}{|c|}{ Colloidal Au NPs } & \multicolumn{2}{|l|}{$\mathrm{Au} / \mathrm{TiO}_{2}$} & \multirow[b]{2}{*}{$\begin{array}{l}\text { Av. EXAFS NP } \\
\text { size }^{a} \\
(\text { nm (ref. 59)) }\end{array}$} \\
\hline & & & & $\begin{array}{l}\text { Av. TEM NP } \\
\text { size (nm) }\end{array}$ & $\mathrm{CN}_{\mathrm{Au}-\mathrm{Au}}$ & $\begin{array}{l}\text { NP size }{ }^{a} \\
\text { (nm (ref. 59)) }\end{array}$ & $\begin{array}{l}\text { Av. TEM NP } \\
\text { size (nm) }\end{array}$ & $\mathrm{CN}_{\mathrm{Au}-\mathrm{Au}}$ & \\
\hline $\mathrm{A}_{1}$ & 1 & 100 & 492 & $3.0 \pm 0.9$ & $9.3 \pm 0.6$ & 1.6 & $2.7 \pm 0.7$ & $10 \pm 0.7$ & 2.0 \\
\hline B & 1 & 50 & 495 & - & $9.2 \pm 0.9$ & 1.5 & $2.3 \pm 0.6$ & $9.5 \pm 0.8$ & 1.6 \\
\hline $\mathrm{C}$ & 1 & 1000 & 498 & $4.6 \pm 1.5$ & $9.4 \pm 0.4$ & 1.6 & $4.0 \pm 1.0$ & $10.3 \pm 0.5$ & 2.3 \\
\hline $\mathrm{A}_{2}$ (ref. 16) & 25 & 100 & 493 & - & $9.8 \pm 0.5$ & 1.9 & $2.9 \pm 0.9$ & $8.4 \pm 0.3$ & 1.4 \\
\hline$A_{3}$ (ref. 16) & 50 & 100 & $500-510$ & - & $10.2 \pm 0.7$ & 2.2 & $2.8 \pm 0.9$ & $9.5 \pm 0.3$ & 1.9 \\
\hline $\mathrm{A}_{4}$ (ref. 16) & 75 & 100 & 538 & - & $10.3 \pm 0.7$ & 2.3 & $3.3 \pm 0.8$ & $11.2 \pm 0.4$ & - \\
\hline
\end{tabular}

${ }^{a}$ The error in the process of calculating particle size from $1^{\text {st }}$ shell coordination number has an intrinsic error of $0.1 \mathrm{~nm}$. $\mathrm{CN}_{\mathrm{Au}-\mathrm{Au}}$ refers to the $\mathrm{Au}-\mathrm{Au}$ coordination number found by fitting the experimental EXAFS data using the Artemis software package, ${ }^{49}$ NP EXAFS fits are shown in Fig. S6. The remaining Au first shell fitting parameters for all samples can be found in Table S1.

windows. A low flow rate of $1 \mathrm{~mL} \min ^{-1}$ was applied to limit beam damage to the Au NPs${ }^{47}$ and also prevent the evolution of $\mathrm{H}_{2}$ gas from excess $\mathrm{NaBH}_{4}$ reaction along the tubing walls. $1 \mathrm{wt} \% \mathrm{Au} / \mathrm{TiO}_{2}$ powder catalysts were studied ex situ and prepared for testing as $8 \mathrm{~mm}$ pellets and placed in a X-ray transparent cell. In situ XAFS measurements were made in fluorescence mode using a $\mathrm{Si}(111)$ four-bounce monochromator, data was collected through a 64 element Ge fluorescence detector with the xpress 2 digital pulse processor. ${ }^{48}$ Scans were performed at a time resolution of $43 \mathrm{~min}$ per spectrum $\left(K_{\max }=18\right)$, with 6 scans collected for the colloidal solutions and 3 for the powder catalysts. Processing and normalization of the absorption spectra and analysis of the extended X-ray absorption fine-structure (EXAFS) were accomplished using IFEFFIT with the Horae package (Athena and Artemis). ${ }^{49,50}$ Experimental determination of the amplitude reduction factor, $S_{0}{ }^{2}$, was achieved through EXAFS data analysis of the $\mathrm{Au}$ foil spectrum, giving the fixed parameter of 0.83 . EXAFS data fittings were made with $R$-space within a fit range of $1.74<R<3.37 \AA$ (for both colloidal and $\mathrm{TiO}_{2}$ supported Au NPs) and a $k$-space of $3<k<11.5$ (colloidal Au NPs) and $3<k<14\left(\mathrm{TiO}_{2}\right.$ supported Au NPs).

Transmission electron microscopy (TEM). Preparation of the samples for TEM imaging required the initial dispersion of the catalyst in high purity ethanol utilizing ultra-sonication over a 30 minute period, $40 \mu \mathrm{L}$ of this solution was dropped and evaporated onto a holey carbon film supported by a 300 mesh $\mathrm{Cu}$ TEM grid. A JEOL JEM $2100 \mathrm{EM}$ was used to study the $\mathrm{Au} /$ $\mathrm{TiO}_{2}$ samples.

Scanning TEM high angle annular dark field (STEM HAADF). For imaging of the colloidal Au NPs, a drop of the colloid solution was placed on a holey carbon TEM grid and allowed to dry in air. Samples with Au concentrations 50, 100 and 1000 $\mu \mathrm{M}$ were examined using a JEM 2800 (Scanning) TEM. High angle annular dark-field (HAADF) imaging in scanning mode used an off-axis annular detector. Secondary electron signals were acquired simultaneously with other STEM images, providing topological information of the samples. X-ray emission detection was performed of the sample in scanning mode.

\section{Results and discussion}

Ultraviolet-visible (UV-vis) spectroscopy has been used to study both the $\mathrm{Au}$ precursor solution (reduction rate) and the formation of Au NPs through the formation of surface plasmon resonance (SPR) band before immobilization..$^{51-53}$ The position of the SPR peak, shown in Fig. S1, $\dagger \lambda_{\max }$, is related to the particle size and shape of NPs; a shift to higher wavelength is indicative of an increase in Au particle size. ${ }^{51}$ The intensity of the band can also give a measure of particle size, as larger particles give more intense peaks, however, in this study there is a correlation of parameters with both particle size and concentration contributing towards this. It has been previously reported that the size of Au NPs supported on $\mathrm{TiO}_{2}$ can be tailored by systematic control of the temperature of reduction of Au precursor salts; an increase in reduction temperature has the effect of increasing the particle size of the supported Au NPs. ${ }^{51-53}$ This observation was repeated in this work (Table 1); as the temperature increases from $25^{\circ} \mathrm{C}$ to $75^{\circ} \mathrm{C}\left(\mathrm{A}_{1}-\mathrm{A}_{4}\right)$, the position of $\lambda_{\max }$ shifts from $493 \mathrm{~nm}$ to $538 \mathrm{~nm}$, indicating a growth in particle size. The first series of Au colloidal solutions were all prepared using an initial $\mathrm{Au}$ concentration of $100 \mu \mathrm{M}$. However, for the $1{ }^{\circ} \mathrm{C}$ reduction temperature two additional concentrations, $50 \mu \mathrm{M}$ and $1000 \mu \mathrm{M}$ (B and C), were also investigated. For this variable concentration series, there were no discernible changes to the SPR $\lambda_{\max }$, the broad nature of these bands makes it difficult to extract any quantifiable assessment of the particle size characteristics. $^{54}$

When analysing the properties of colloidal NPs at concentrations comparable to those employed previously, ${ }^{55} \mathrm{UV}$-vis and TEM both provide an incomplete description. The broad nature of the Au SPR band and the challenge of measuring colloidal solutions using TEM without causing aggregation of the colloidal NPs (Fig. 2a-c), does not capture sufficient detail to make a reliable comparison between supported and unsupported Au NPs. Recent advances through the increased flux of modern insertion device-based beamlines and multi-element fluorescence detectors, have allowed XAFS to provide a suitable tool for studying both unsupported and supported NP catalysts while avoiding beam damage (Fig. 2, S7 and S8†). 

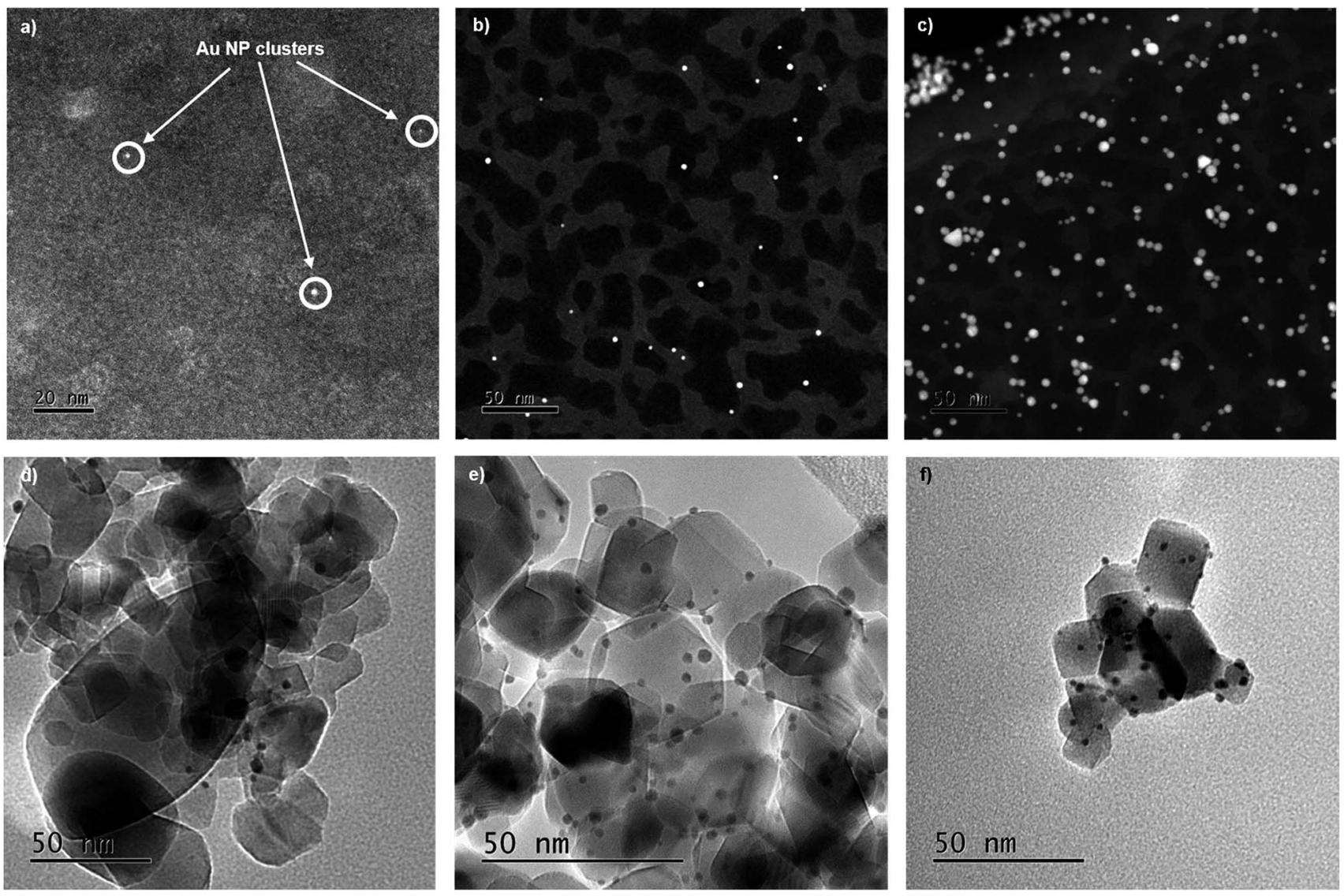

Fig. 2 (a-c) STEM HAADF of Au colloids prepared using increasing Au concentration at $1^{\circ} \mathrm{C}$, (a) $50 \mu \mathrm{M}$ (B) $100 \mu \mathrm{M}$ (C) $1000 \mu \mathrm{M}$ droppered onto a holey carbon TEM grid, (d-f) TEM images of the $\mathrm{TiO}_{2}$ supported colloidal Au, with immobilization performed at $1^{\circ} \mathrm{C}$ (d) $50 \mu \mathrm{M}$ (e) $100 \mu \mathrm{M}$ ( $f$ ) $1000 \mu \mathrm{M}$.

The high energy and stability of the I20-scanning beamline at Diamond Light Source, U.K., has been used to acquire reliable XAFS data, at the $\mathrm{Au} \mathrm{L}_{3}$-edge, of our colloidal and $\mathrm{TiO}_{2}$ supported Au NPs (Fig. 3). ${ }^{48}$ The normalised XANES spectra (Fig. 3a) of colloidal $\mathrm{Au}$ prepared at variable temperature (samples $\mathrm{A}_{1-4}$ ) are characterised by the absence of an intense white line peak at $\sim 11915 \mathrm{eV}$, which is indicative of $\mathrm{Au}^{0}$ being the only species in solution; the white line arises due to dipole allowed $2 \mathrm{p}$ to $5 \mathrm{~d}$ transitions, as $\mathrm{Au}^{0}$ has a full d-shell there is not an intense main edge transition, as seen in Fig. S2. $\uparrow^{29,31,56}$ On assessing the colloidal solutions as a function of temperature, we observe that the feature at $\sim 11946 \mathrm{eV}$ increases in intensity; the change in this feature is more pronounced and easier to observe when plotting the XANES data in its $1^{\text {st }}$ derivative form (Fig. $3 \mathrm{~b}$ ). This continuum feature has been ascribed previously to $\mathrm{Au}-\mathrm{Au}$ multiple scattering interactions and is linked to the particle size of the Au NPs. ${ }^{29,57,58}$ The larger the particle size, the higher the amount of multiple scattering from $\mathrm{Au}-\mathrm{Au}$ interactions, resulting in an increase in the intensity of this feature. Varying the concentration of $\mathrm{Au}$ precursors $\left(\mathrm{A}_{1}-\mathrm{C}\right)$, however, does not appear to have an effect on the normalised XANES spectra (Fig. 3d), or the first derivative spectra (Fig. 3e). The absence of the multiple scattering post edge feature suggests that for all three samples, $\mathrm{A}_{1}-\mathrm{C}$, the particle size is $\leq 2 \mathrm{~nm} .^{29,57,58}$
The EXAFS analysis, however, can be used to obtain quantitative information on the colloidal NP size. Fig. 3c shows the $k^{3}$-weighted forward Fourier transform EXAFS spectra for samples $\mathrm{A}_{1}-\mathrm{A}_{4}$, EXAFS chi data can be found in Fig. $\mathrm{S} 4 . \dagger$ It is evident that there is a change in intensity of the feature located at $\sim 2.8 \AA$ as the temperature of reduction increases. This feature arises as a consequence of $1^{\text {st }}$ shell $\mathrm{Au}-\mathrm{Au}$ scattering interactions and the intensity of this peak can be correlated to an increase in the $\mathrm{Au}-\mathrm{Au}$ coordination number (CN), which, in turn, shows the trend in particle size. With smaller Au NPs having a higher surface fraction there is a greater proportion of under coordinated surface Au atoms, leading to decreases in the average $\mathrm{Au}-\mathrm{Au} \mathrm{CN}{ }^{60}$

Calculations of the average Au NP sizes, were performed using methods reported by Beale et al. ${ }^{59}$ XAFS spectra were modelled based on different particle sizes assuming all Au NPs are; (1) spherical in shape, (2) FCC in packing and (3) $<3 \mathrm{~nm}$ in diameter. A similar approach was used for samples $\mathrm{A}_{1}, \mathrm{~B}$, and $\mathrm{C}$, where no changes can be seen in the Fourier transform EXAFS spectra, or in the generated fitting parameters.

The particle sizes obtained from the fits confirmed that, within the error of the measurement, adjusting the concentration of the $\mathrm{Au}$, between $50-1000 \mu \mathrm{M}$, precursor does not alter the size of the colloidal NPs produced. This is an important observation 

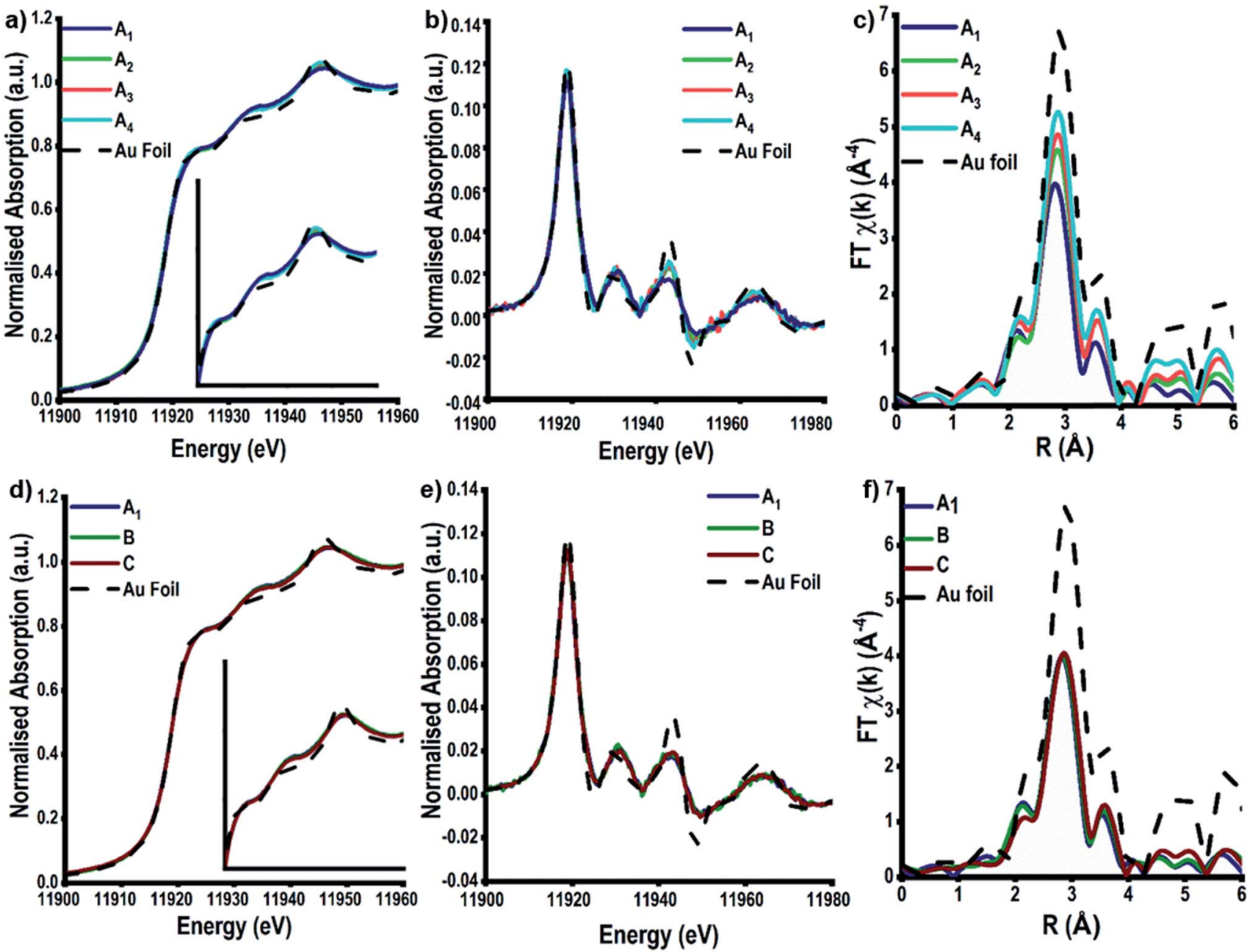

Fig. 3 XAFS taken at the Au $\mathrm{L}_{3}$-edge of the colloidal Au samples; (a $\&$ d) XANES spectra for the colloidal Au detailing change as a result of increasing synthesis temperature and Au concentration, ( $b \&$ e) the normalised first derivative of the absorption for the temperature and Au concentration influenced colloids respectively and (c \& f) experimental Fourier transform (FT) chi $(k)$ data of the corresponding EXAFS signals for colloidal Au showing the influence of temperature and Au concentration.

as it is already known that for sol-immobilization, increasing the concentration of initial precursor solutions manifests itself as an increase of supported $\mathrm{Au}$ NP sizes. ${ }^{55}$ However, we can now confirm that this effect occurs only during the immobilization phase and not in the preformed colloidal NPs.

To assess the effect of immobilization, the corresponding $\mathrm{Au} / \mathrm{TiO}_{2}$ materials (from solutions of $\mathrm{A}_{1}, \mathrm{~B}$, \& $\mathrm{C}$ ) were prepared and XAFS data were acquired (Fig. $\mathrm{S} 6 \dagger$ ); as the Au precursor concentration increases from $50-1000 \mu \mathrm{M}$, the NPs size increases from 1.6 to $2.3 \mathrm{~nm}$. This in direct contrast with the results obtained for the colloidal Au NPs, where all the particles have approximately the same particle size.

A possible explanation for this behaviour could be attributed to the mobility of NPs on the support surface. As the synthesis temperature reaches the Hüttig $\left(\mathrm{TH}=0.3 T_{\text {melting }}[K]\right)$ and Tamman temperatures ( $\mathrm{TT}=0.5 T_{\text {melting }}[K]$ ), the surface atoms and bulk atoms respectively become mobile, ${ }^{61}$ constituting a mechanism for particle mobility. ${ }^{62}$ For NPs $\sim 2 \mathrm{~nm}$ in size, as observed in the colloidal solutions, the $T_{\text {melting }}$ can be as low as $\sim 330{ }^{\circ} \mathrm{C},{ }^{63}$ giving $\mathrm{TH} \sim-93{ }^{\circ} \mathrm{C}$ and TT $\sim 25{ }^{\circ} \mathrm{C} .{ }^{64}$ We suggest that with a higher concentration of the $\mathrm{Au}$ precursor and subsequent increase in surface NP density, coupled with slow migration of the mobile surface atoms yields NP growth through Ostwald ripening. ${ }^{65}$ Contrary to this, when preparing the colloid with a lower concentration, NPs are dispersed with larger interparticle distances, revealing negligible changes to NP size pre- and post-immobilization.

A comprehensive explanation for this behaviour has yet to be given in literature, but a further plausible reason could be a saturation of anchoring sites on the surface of the support, which, in turn, force the coalescence of the non-anchored nanoparticles. In the case presented the general $\mathrm{Au} w \mathrm{t} \%$ does not change amongst the samples, however, a possible change in local particle density during the immobilization phase could cause a growth in the particles due to a similar phenomenon, as the one shown by changing the metal loading. ${ }^{34}$ Regardless of the cause for the increase in size, it is clear that the in order to fully design and optimise supported NPs it is crucial to understand the relatively underexplored immobilization process; this is a key point in directing the resultant NP properties. 


\section{Conclusions}

This work demonstrates that XAFS is a suitable method to extract quantifiable structural data on ultra-dilute solutions of colloidal Au NPs $(50 \mu \mathrm{M})$, akin to those commonly used in solimmobilization processes. These studies have revealed several key findings: (i) the particle size of the colloidal Au is dependent on the temperature of reduction, with lower temperatures generating smaller particles, (ii) the concentration of $\mathrm{Au}$ precursor does not influence the size of the formed colloidal NPs within the range of 50 to $1000 \mu \mathrm{M}$ and (iii) the immobilization stage of synthesis influences the Au particle size growth processes. Therefore, controlling and optimising the immobilization step is of paramount importance for the usage of low/ high diluted metal colloidal solutions to synthesize size/shape supported metal nanoparticles.

\section{Funding sources}

All authors acknowledge UK Catalysis Hub Consortium and EPSRC (Grants EP/K014706/1, EP/K014668/1, EP/K014854/1, EP/ K014714/1, and EP/I019693/1). D. D. and P. P. 'W. acknowledge further support through the STFC ST/R002754/1.

\section{Conflicts of interest}

There are no conflicts to declare.

\section{Abbreviations}

$\begin{array}{ll}\mathrm{NP} & \text { Nanoparticle } \\ \mu \mathrm{M} & \text { Micromolar }\left(10^{-6} \text { molar }\right) \\ \mathrm{SPR} & \text { Surface plasmon resonance } \\ \mathrm{CN} & \text { Coordination number }\end{array}$

\section{Data access statement}

All data supporting this study are openly available from the University of Southampton repository at https://doi.org/ 10.5258/SOTON/D0921.

\section{Acknowledgements}

The authors wish to acknowledge the Diamond Light Source for provision of the beamtime (SP17283). The $\mathrm{RCaH}$ are also acknowledged for use of facilities and support of their staff. The electron microscopy department of Johnson Matthey Technology Centre, Sonning Common are acknowledged for their support in imaging Au colloids, both in Sonning Common and at the ePSIC facility at Harwell Science and Innovation Centre, Didcot, OX11 0DE, UK. G. Malta for contribution of $\mathrm{HAuCl}_{4}$ XAFS reference data used in ESI. $\dagger$ UK Catalysis Hub is kindly thanked for resources and support provided via our membership of the UK Catalysis Hub Consortium and funded by EPSRC grant: EP/K014706/2, EP/K014668/1, EP/K014854/1,
$\mathrm{EP} / \mathrm{K} 014714 / 1$ or EP/M013219/1. The authors wish to thank the STFC GCRF START project for funding the position of Donato Decarolis. N. Abdullah would like to acknowledge the Ministry of Education, Malaysia (MOE) for their financial support through post-doctoral funding.

\section{Notes and references}

1 A. R. Tao, S. Habas and P. Yang, Small, 2008, 4, 310-325.

2 T. Teranishi and M. Miyake, Chem. Mater., 1998, 10, 594-600.

3 Y. Sun and Y. Xia, Science, 2002, 298, 2176-2179.

4 T. Ahmadi and Z. Wang, Science, 1996, 272, 1994-1996.

5 S. M. Rogers, C. R. A. Catlow, C. E. Chan-Thaw, A. Chutia, N. Jian, R. E. Palmer, M. Perdjon, A. Thetford, N. Dimitratos, A. Villa and P. P. Wells, ACS Catal., 2017, 7, 2266-2274.

6 Y. Zhang, J. Yu, H. Niu and H. Liu, J. Colloid Interface Sci., 2007, 313, 503-510.

7 O. Rac, P. Suchorska-Wozniak, M. Fiedot and H. Teterycz, Beilstein J. Nanotechnol., 2014, 5, 2192-2201.

8 A. Villa, D. Wang, G. M. Veith, F. Vindigni and L. Prati, Catal. Sci. Technol., 2013, 3, 3036-3041.

9 L. Prati and A. Villa, Acc. Chem. Res., 2014, 47, 855-863.

10 P. K. Khanna, P. V. More, J. P. Jawalkar and B. G. Bharate, Mater. Lett., 2009, 63, 1384-1386.

11 S. Pillai and P. V. Kamat, J. Mater. Chem. B, 2004, 108, 945951.

12 S. Link and M. A. El-Sayed, J. Phys. Chem. B, 1999, 103, 42124217.

13 N. Moloto, N. Revaprasadu, P. . Musetha and M. Moloto, J. Nanosci. Nanotechnol., 2009, 9, 4760-4766.

14 L. Prati and A. Villa, Catalysts, 2011, 2, 24-37.

15 L. Prati and A. Villa, in Gold Catalysis: Preparation, Characterization, and Applications, CRC Press, 2016, pp. 5963.

16 S. M. Rogers, C. R. A. Catlow, C. E. Chan-thaw, D. Gianolio, E. K. Gibson, A. L. Gould, N. Jian, A. J. Logsdail, R. E. Palmer, L. Prati, N. Dimitratos, A. Villa and P. P. Wells, ACS Catal., 2015, 5, 4377-4384.

17 T. Teranishi and M. Miyake, Chem. Mater., 1998, 4756, 594600.

18 J. Kimling, M. Maier, B. Okenve, V. Kotaidis, H. Ballot and A. Plech, J. Phys. Chem. B, 2006, 110, 15700-15707.

19 H. Borchert, E. V. Shevchenko, A. Robert, I. Mekis, A. Kornowski, G. Grübel and H. Weller, Langmuir, 2005, 21, 1931-1936.

20 A. Gniewek, A. M. Trzeciak, J. J. Ziółkowski, L. K $\square$ piński, J. Wrzyszcz and W. Tylus, J. Catal., 2005, 229, 332-343.

21 J. Polte, T. T. Ahner, F. Delissen, S. Sokolov, F. Emmerling, A. F. Thünemann and R. Kraehnert, J. Am. Chem. Soc., 2010, 132, 1296-1301.

22 J. Ohyama, K. Teramura, T. Shishido, Y. Hitomi, K. Kato, H. Tanida, T. Uruga and T. Tanaka, Chem. Phys. Lett., 2011, 507, 105-110.

23 T. Sakai and P. Alexandridis, J. Phys. Chem. B, 2005, 109, 7766-7777. 
24 B. Abécassis, F. Testard, Q. Kong, B. Francois and O. Spalla, Langmuir, 2010, 26, 13847-13854.

25 L. Yang, H. Cheng, Y. Jiang, T. Huang, J. Bao, Z. Sun, Z. Jiang, J. Ma, F. Sun, Q. Liu, T. Yao, H. Deng, S. Wang, M. Zhu and S. Wei, Nanoscale, 2015, 7, 14452-14459.

26 M. Harada and S. Kizaki, Cryst. Growth Des., 2016, 16, 12001212.

27 T. Shibata, H. Tostmann, B. Bunker, A. Henglein, D. Meisel, S. Cheong and M. Boyanov, J. Synchrotron Radiat., 2004, 8, 545-547.

28 J. Ohyama, K. Teramura, Y. Higuchi, T. Shishido, Y. Hitomi, K. Kato, H. Tanida, T. Uruga and T. Tanaka, ChemPhysChem, 2010, 12, 127-131.

29 T. Yao, Z. Sun, Y. Li, Z. Pan, H. Wei, Y. Xie, M. Nomura, Y. Niwa, W. Yan, Z. Wu, Y. Jiang, Q. Liu and S. Wei, J. Am. Chem. Soc., 2010, 132, 7696-7701.

30 M. Harada, K. Saijo and N. Sakamoto, Colloids Surf., A, 2009, 349, 176-188.

31 M. Giorgetti, G. Aquilanti, B. Ballarin, M. Berrettoni, M. C. Cassani, S. Fazzini, D. Nanni and D. Tonelli, Anal. Chem., 2016, 88, 6873-6880.

32 F. Hubert, F. Testard, A. Thill, Q. Kong, O. Tache and O. Spalla, Cryst. Growth Des., 2012, 12, 1548-1555.

33 S. Skou, R. E. Gillilan and N. Ando, Nat. Protoc., 2014, 9, 1727.

34 J. Kennedy, W. Jones, D. J. Morgan, M. Bowker, L. Lu, C. J. Kiely, P. P. Wells and N. Dimitratos, Catal., Struct. React., 2015, 1, 35-43.

35 B. G. Trewyn, I. I. Slowing, S. Giri, H. Chen and V. S. Lin, Acc. Chem. Res., 2007, 40(9), 846-853.

36 S. Ayyappan, R. S. Gopalan, G. N. Subbanna and C. N. R. Rao, J. Mater. Res., 1997, 12, 398-401.

37 J. A. Trindell, J. Clausmeyer and R. M. Crooks, J. Am. Chem. Soc., 2017, 139, 16161-16167.

38 M. Bowker, C. Morton, J. Kennedy, H. Bahruji, J. Greves, W. Jones, P. R. Davies, C. Brookes, P. P. Wells and N. Dimitratos, J. Catal., 2014, 310, 10-15.

39 M. M. Maye, J. Luo, I.-I. S. Lim, N. N. Kariuki, D. Rabinovich and C.-J. Zhong, J. Am. Chem. Soc., 2003, 125, 9906-9907.

40 K. R. Brown and M. J. Natan, Langmuir, 1998, 14, 726-728.

41 X.-M. Li, M. R. de Jong, K. Inoue, S. Shinkai, J. Huskens and D. N. Reinhoudt, J. Mater. Chem., 2001, 11, 1919-1923.

42 M. Boronat and A. Corma, Langmuir, 2010, 26, 16607-16614. 43 B. S. Lee, Y. S. Chi, J. K. Lee, I. S. Choi, C. E. Song, S. K. Namgoong and S. Lee, J. Am. Chem. Soc., 2004, 126, 480-481.

44 B. Roldan Cuenya, M. Alcántara Ortigoza, L. K. Ono, F. Behafarid, S. Mostafa, J. R. Croy, K. Paredis, G. Shafai,
T. S. Rahman, L. Li, Z. Zhang and J. C. Yang, Phys. Rev. B: Condens. Matter Mater. Phys., 2011, 84, 1-14.

45 M. Comotti, W. Li, B. Spliethoff and F. Schu, J. Am. Chem. Soc., 2006, 917-924.

46 B. R. Cuenya, Thin Solid Films, 2010, 518, 3127-3150.

47 J. G. Mesu, A. M. Beale, F. M. F. De Groot and B. M. Weckhuysen, J. Phys. Chem. B, 2006, 110, 17671-17677. 48 S. Hayama, G. Duller, J. P. Sutter, M. Amboage, R. Boada,

A. Freeman, L. Keenan, B. Nutter, L. Cahill, P. Leicester, B. Kemp, N. Rubies and S. Diaz-moreno, J. Synchrotron Radiat., 2018, 25, 1556-1564.

49 M. Newville, J. Synchrotron Radiat., 2001, 8, 96-100.

50 B. Ravel, in X-ray Absorption and X-ray Emission Spectroscopy.

Theory and Applications, ed. J. A. van Bokhoven and C. Lamerbiti, Wiley, 2016, p. 283.

51 V. Amendola, R. Pilot, M. Frasconi, O. M. Maragò and A. M. Iati, J. Phys.: Condens. Matter, 2017, 29, 203002.

52 X. Zhou, G. Liu, J. Yu and W. Fan, J. Mater. Chem., 2012, 22, 21337.

53 L. Xu, J. Peng, C. Srinivasakannan, L. Zhang, D. Zhang,

C. Liu, S. Wang and A. Q. Shen, RSC Adv., 2014, 4, 25155.

54 X. Huang and M. A. El-Sayed, J. Adv. Res., 2010, 1, 13-28.

55 N. Dimitratos, A. Villa, L. Prati, C. Hammond, C. E. ChanThaw, J. Cookson and P. T. Bishop, Appl. Catal., A, 2016, 514, 267-275.

56 Z. Song, J. P. L. Kenney, J. B. Fein and B. A. Bunker, Geochim. Cosmochim. Acta, 2012, 86, 103-117.

57 M. Harada and H. Einaga, Langmuir, 2007, 23, 6536-6543.

58 Y. M. Yiu, P. Zhang and T. K. Sham, Nanotechnology, 2003, 3, 183-186.

59 A. M. Beale and B. M. Weckhuysen, Phys. Chem. Chem. Phys., 2010, 12, 5562-5574.

60 W. Szczerba, H. Riesemeier and A. F. Thünemann, Anal. Bioanal. Chem., 2010, 398, 1967-1972.

61 J. A. Moulijn, A. E. van Diepen and F. Kapteijn, Appl. Catal., A, 2001, 212, 3-16.

62 T. W. Hansen, A. T. DeLaRiva, S. R. Challa and A. K. Datye, Acc. Chem. Res., 2013, 46, 1720-1730.

63 G. Guenther and O. Guillon, J. Mater. Sci., 2014, 49, 79157932.

64 D. James Martin, D. Decarolis, Y. I. Odarchenko, J. J. Herbert, T. Arnold, J. Rawle, C. Nicklin, H.-G. Boyen and A. M. Beale, Chem. Commun., 2017, 53, 5159-5162.

65 W. Z. Ostwald, Z. Phys. Chem., 1900, 34, 495-503.

66 S. Diaz-Moreno, M. Amboage, M. Basham, R. Boada, N. E. Bricknell, G. Cibin, T. M. Cobb, J. Filik, A. Freeman, K. Geraki, D. Gianolio, S. Hayama, K. Ignatyev, L. Keenan, I. Mikulska, J. Frederick, W. Mosselmans, J. J. Mudd and S. A. Parry, J. Synchrotron Radiat., 2018, 1-12. 